\title{
EL PERFORMANCE NARRATIVO DE LA VIOLENCIA DE LAS AUTODEFENSAS DE
} TIERRA CALIENTE MÉXICO

\author{
Miguel Ángel Vite Pérez ${ }^{1}$
}

\begin{abstract}
Resumen
El propósito del artículo es interpretar mediante la narrativa binaria (buenos/malos) aparecida en la prensa escrita de las autodefensas de tierra caliente (Michoacán) en un escenario de conflicto armado. Donde se expresaron los motivos de los principales protagonistas, reproduciendo la representación social de la inseguridad pública, identificada con las actividades ilegales de los diferentes grupos de narcotraficantes, sin considerar que su violencia es parte de un método particular de despojo legitimado por la debilidad de los valores civiles de inclusión y solidaridad. Además, que en el conflicto armado prevaleció la ilegalidad que se articuló con valores excluyentes donde la vida humana no fue visualizada como un derecho humano. Al mismo tiempo, se fortaleció la idea de que la inseguridad pública regional era resultado de la multiplicación de los grupos criminales en complicidad o no con las autoridades locales. Mientras, la perspectiva usada se basó en la propuesta derivada del punto de vista de la sociología cultural de Jeffrey Alexander.
\end{abstract}

Palabras clave: Narración binaria, motivos, violencia, narcotráfico, performance.

\section{Introducción}

La interacción social se manifiesta como un hecho colectivo dotado de significado e interpretado a través de los motivos de parte de los que participan y los observan. Dichas interpretaciones se han configurado a través de narrativas que se han expresado mediante los valores (creencias) y que han generado clasificaciones (dicotómicas), en la llamada esfera civil, formada por las instituciones comunicativas y regulativas, donde la acción social se convierte en simbólica (ALEXANDER, 2013).

Por tal motivo, la acción social es simbólica porque sólo se comprende a través de sus significados, donde subyace su inteligibilidad e interpretación, articulada a diversas visiones del mundo y expresadas como un hecho comunicativo. Este hecho comunicativo se escenifica también mediante representaciones sociales compartidas (KUPER, 2001).

${ }^{1}$ Instituto Politécnico Nacional - IPN. Méxicol. E-mail: miguelviteperez@yahoo.com.mx 
Por eso, la acción colectiva armada de las autodefensas de tierra caliente (Michoacán), fue considerada como un hecho comunicativo, escenificado como violencia (performance), lo que expresó, desde un punto de vista general, la creencia colectiva identificada como inseguridad pública, legitimando, al mismo tiempo, el uso de la fuerza dirigida contra las personas que fueron clasificadas a priori como las productoras de una situación social de despojo y robo (MALDONADO, 2014).

De este modo, la violencia ejercida como fuerza armada de parte de las autodefensas de tierra caliente contra los supuestos causantes de su inseguridad social, se expresó como una narrativa en la esfera civil, donde los valores e ideales proyectaron aspiraciones y temores colectivos. Su aspiración para "liberarse", por ejemplo, de las acciones de despojo y robo realizadas por la organización de narcotraficantes regional (Los Caballeros Templarios) que iban en contra del ideal de conservación de la cohesión social o solidaridad en las comunidades de la región.

Sin embargo, también evidenció las disputas por el uso de la violencia en la esfera civil apelando los valores democráticos (más incluyentes o universales) o los valores contrarios que generan procesos excluyentes, de estigmatización y segregación, hasta de mayor violencia, basados también en creencias identificados como orden o desorden (ALEXANDER, 2006, 194).

En consecuencia, para el estudio del significado de la acción colectiva armada de las autodefensas fue de utilidad observarla también como un drama social en la esfera civil, donde las interpretaciones expresaban la debilidad del Estado mexicano para garantizar la seguridad pública, lo que favoreció el surgimiento de grupos civiles armados y las acciones criminales de los narcotraficantes.

El propósito del artículo fue la elaboración de una interpretación ${ }^{2}$ a partir de un hecho colectivo comunicativo en la esfera civil de la acción social armada en tierra caliente (Michoacán), cuyo discurso binario era contrario al valor universal de la inclusión, derivado del modelo de la democracia liberal ${ }^{3}$, ausente en el escenario social de tierra caliente ${ }^{4}$.

\footnotetext{
${ }^{2}$ De acuerdo con Geertz (2006: 32), el tipo de descripción que se utilizó fue más interpretativo porque lo que se interpretó fue el flujo del discurso social, es decir, se trató de rescatar lo dicho como discurso fijado en los medios establecidos para su consulta (periódicos, revistas, etc.). Esto fue la base de la interpretación que se elaboró en este artículo.

${ }^{3}$ En el caso mexicano algunos intelectuales de la transición democrática pensaron que el modelo político de la democracia electoral establecería las bases para que el conflicto por el poder político entre la élite organizada a través de un sistema de partidos disminuyera, y de esta manera, se garantizaría un acceso general tanto de líderes como de ciudadanos a los diferentes niveles de representación política, eliminando, en consecuencia, la violencia (WOLDENBER, 2012).

${ }^{4}$ Tierra caliente se localiza en la parte sur del estado de Michoacán y ha sido definida así por sus características climáticas y de su suelo. Clima tropical, territorio formado por miles de pliegues de la sierra, donde se encuentran los municipios de Apatzingán, Parácuaro, Francisco Múgica (Conocido más como Nueva Italia), Buena Vista Tomatlán,
} 
La acción social de las autodefensas armadas de tierra caliente expresada como hechos comunicativos, fueron narrativas que argumentaron que el combate contra la delincuencia organizada era una lucha contra los negocios ilegales del narcotráfico (ASTORGA, 2015).

En este sentido, la inseguridad pública mexicana, como discurso colectivo, ha servido para clasificar las actividades sociales ilegales como acciones de buenos y malos, lo que favorece el uso de la fuerza como violencia contra las acciones sociales clasificadas como ilegales (DAS, 2016, 91-100).

Para el caso mexicano, el significado de la ilegalidad colectiva de los pobres está ligada a la narrativa de la justicia social ${ }^{5}$, articulada también con otra narrativa que ha establecido la supuesta debilidad de las instituciones estatales de bienestar social ${ }^{6}$, estudiada más como una negación de los derechos sociales (DUHAU y GIGLIA, 2008).

Pero también ésa narrativa de la justicia social ha encontrado otro soporte en la presencia de una representación social ${ }^{7}$, que ha identificado la reproducción de las situaciones de precariedad y vulnerabilidad-pobreza y miseria-mediante los programas de asistencia social estatal (BAYÓN, 2015, 89-90).

En este caso, la narrativa de la pobreza y la miseria, desde el punto de vista de Wacquant (2000, 21-24), expresó una "falla" del sistema capitalista neoliberal al crear personas violentas que no tenían una funcionalidad social en el nuevo régimen (CASTEL, 2004; CASTEL y HAROCHE, 2003; WACQUANT, 2009, 13-28). Violencia, según ésa argumentación, que no cesaría debido a la

Tecaltepec Aguililla, Churumuco y Lázaro Cárdenas (que es un puerto de salida hacia el Pacífico). Pero la rebelión armada de las autodefensas inició en Tepalcatepec, Buena Vista Tomatlán (conocido como La Ruana), Coalcomán, y se extendió a los siguientes municipios: Chinicuila, Aguililla, Aquila y Tancitaro, cuya característica es que son los más extensos y con escasa población, sobre todo, porque existen decenas de poblados con menos de 200 habitantes (MARTÍNEZ ELORRIAGA, 2014).

${ }^{5}$ Por eso en México la representación social del bandido como evasor de la ley es para mostrar que la ilegalidad tiene como función otorgar bienestar a los pobres o excluidos de las ventajas sociales concentradas en los grupos sociales privilegiados (DOMÍNGUEZ, 2015).

${ }^{6}$ Este hecho muestra lo que Alain Touraine $(2016,14-15)$ ha analizado como una separación entre actor y sistema. En otras palabras, la acción social ha dejado de estar subordinada a la estructura o sistema, lo que ha visualizado como una consecuencia del neoliberalismo. Pero para el caso mexicano es más un asunto de configuración histórica de las instituciones estatales y del papel que ha tenido la acción social armada en las mismas (PANTERS, 2012). En consecuencia, niega la perspectiva de Touraine la autonomía de la acción colectiva, lo que no comparto.

${ }^{7}$ Las representaciones sociales son sistemas cognitivos donde las creencias, normas, imágenes, opiniones, metáforas expresan interpretaciones, actitudes y prácticas positivas y negativas (binarias), donde no sólo existe consenso sino también conflicto y luchas simbólicas (ABRIL, 2004, 11-32). 
generalización de los empleos precarios ${ }^{8}$, sin derechos sociales ${ }^{9}$ (BECK, 2006; SOTELO, 2010, 139141).

Por ello, los discursos académicos creados en México se han construido retomando las anteriores ideas, sin embargo, se destaca una en particular: la violencia ha sido provocada, en el plano regional, por los "vacíos" del poder político o porque existen "márgenes" en la formación del Estado nacional (BUSCAGLIA, 2015; MALDONADO, 2010).

Pero dichas narrativas están basadas en la visión estructuralista ${ }^{10}$, que niega la dinámica autónoma de la acción social y el papel de la cultura como externalización de los significados subjetivos, lo que también se puede analizar insisto, como un hecho comunicativo, construido como un discurso binario (ALEXANDER, 2010, 283).

El artículo se dividió en cuatro partes, en la primera se construyó la metodológica usada para mostrar de manera resumida, la comprensión de la acción social de las autodefensas y de Los Caballeros Templarios a través de la propuesta de la sociología cultural de Jeffrey Alexander. En la segunda parte, se analizó la construcción de la narrativa binaria de las autodefensas como performances o acción simbólica, que definieron como sus enemigos a Los Caballeros Templarios, que habían establecido en Tierra Caliente su método de despojo, basado en la violencia. Mientras, en la tercera parte se estudió la narrativa de otros actores que interpretaron la acción armada de las autodefensas de tierra caliente como una acción ilegal, relacionada con una falta de "seguridad" de parte del Estado.

En la cuarta parte, se caracterizó el nuevo escenario que transformó a las autodefensas en una fuerza punitiva, subordinada a la lógica de la seguridad pública estatal. Posteriormente aparecen las reflexiones finales sobre el performance narrativo de las autodefensas en tierra caliente.

\section{Metodológica de estudio de la acción social simbólica}

En la esfera civil se ha institucionalizado los valores y sus regulaciones de la acción social, caracterizada por compartir valores o creencias y visiones del mundo, generadoras de solidaridad,

\footnotetext{
${ }^{8}$ Es un trabajo que se caracteriza por bajos salarios y con limitados o nulos derechos sociales, lo que amplía la masa de pobres (STANDING, 2013, 17-21).

${ }^{9} \mathrm{La}$ inseguridad y la precariedad como un sentimiento social de temor significaría en el pensamiento de Robert Castel $(2013,35)$ que el individuo no dispone de protecciones importantes porque son frágiles y están amenazadas y porque se tiene miedo a perderlas.

${ }^{10}$ Pierre Bourdieu $(2002,46)$ afirmaba: “... (que) la estructura (...imponía) la forma que pueden adoptar las relaciones visibles de interacción y el contenido mismo de la experiencia que los agentes pueden tener de él”. Es decir, el campo social organiza la acción social e impone la visión que los sujetos tienen del mismo. Nótese que la estructura determina o influye de manera directa en la interacción social y en la conformación de la subjetividad de los individuos.
} 
expresada en la opinión pública. Dicha diversidad de códigos culturales, posibilitan el surgimiento de diversas prácticas sociales, cuyos significados pueden estar vinculados con los valores universales o particulares, internalizados como normas que ayuden a la creación de escenarios comunes o de nuevos escenarios (el performance), garantizado por el libre albedrío (Véase, COLLINS, 2009). En este caso, el análisis se centraría en la acción social no en el individuo que la produce y que algunas interpretaciones de la psicología social han destacado como el factor más relevante para comprender la acción colectiva (GERGEN y GERGEN, 2011, 40-41).

La solidaridad en la esfera civil es compleja y conflictiva donde la conciencia social, que se ha formado como una red de estructuras de sentido de pertenencia mediante códigos simbólicos, ha construido el significado social (ALEXANDER, 2013, 591).

Por otro lado, el discurso o la narrativa binaria de los agentes, según Jeffrey Alexander (2006), se desarrolla en tres esferas de la acción social: la de los motivos (atribuidos a los agentes), la de las relaciones (legítimas e ilegítimas) que se construyen para ligarse con otros actores, y la de las instituciones (es decir, qué tipo de organizaciones se formaron y si están reguladas por normas y también si son incluyentes e impersonales o discrecionales y excluyentes).

\section{Cuadro 1}

Discurso binario de los motivos de los autodefensas/caballeros templarios

\begin{tabular}{|l|l|}
\hline Motivos de las autodefensas & Motivos de Los Caballeros Templarios \\
\hline Inseguridad pública & Seguridad pública \\
\hline Método económico de despojo y expoliación & Cobro por un servicio particular de seguridad \\
\hline Derecho a la defensa armada & $\begin{array}{l}\text { Enemigos por ser parte de otras } \\
\text { organizaciones criminales }\end{array}$ \\
\hline $\begin{array}{l}\text { Recobrar el control de la actividad económica } \\
\text { regional }\end{array}$ & $\begin{array}{l}\text { Inversión del negocio de la venta de drogas } \\
\text { en actividades agrícolas lícitas }\end{array}$ \\
\hline $\begin{array}{l}\text { Legitimidad de su lucha armada } \\
\text { Ilegítima por estar controlada por grupos } \\
\text { rivales de narcotraficantes }\end{array}$ \\
\hline
\end{tabular}

Fuente: Elaboración propia.

El cuadro 1 muestra de manera resumida los motivos expresados como discurso de parte de los agentes enfrentados (las autodefensas y Los Caballeros Templarios). Las autodefensas manifestaron los motivos que originaron su acción colectiva armada, basado en el discurso social de la inseguridad pública, creada por la presencia de un método de despojo particular, basado en la fuerza y coerción, manifestado como cobro de cuotas y manejado de manera discrecional por Los Caballeros Templarios. 
Mientras, Los Caballeros Templarios se muestran como productores de seguridad pública e interpreta, en consecuencia, las acciones armadas de las autodefensas como parte de una disputa por el negocio de la droga, apoyada por organizaciones criminales rivales como la de los Zetas o el cartel Jalisco Nueva Generación.

De esta manera, el discurso binario basado en la inseguridad pública provocó que el performance de la autodefensa armada y del gobierno fuera autentico, es decir, creíble lo que se derivó de las interpretaciones provenientes de la opinión pública en los medios impresos.

\section{Cuadro 2}

La estructura binaria de las relaciones

\begin{tabular}{|l|l|}
\hline Relaciones de las autodefensas & Relaciones de Los Caballeros Templarios \\
\hline Abiertas & Discrecionales \\
\hline Confianza & Sospechosas \\
\hline Credibilidad & Interesadas \\
\hline Enfrentamiento & Explotación \\
\hline
\end{tabular}

Fuente: Elaboración propia.

En el cuadro 2, los tipos de relaciones binarias creadas por la acción social violenta de ambos contendientes. Las autodefensas crearon una organización abierta para integrar a los habitantes de las diversas localidades de la región de Tierra Caliente, porque compartían su mismo ideal de lucha, fortaleciendo, en consecuencia, las relaciones de confianza y credibilidad, adquirieron legitimidad. Pero en el caso de Los Caballeros Templarios su organización estableció relaciones particulares de exclusión y sospecha, entrando en una fase de deslegitimación.

Sin embargo, la lucha simbólica de los líderes de la autodefensa también fue para crear una conciencia nacional colectiva en contra de los productores de la inseguridad pública, que a pesar de que es una representación social, mostró que su realización ha sido interpretada por creencias locales y particulares, lo que no la refuerza como un valor general o universal en la sociedad mexicana.

Cuadro 3

Estructuras binarias institucionales

\begin{tabular}{|l|l|}
\hline Institucional (Los Caballeros Templarios) & Anti-institucional (Autodefensas) \\
\hline Arbitrariedad & Regulación normativa \\
\hline Excluyente & Incluyente \\
\hline Personal & Impersonal \\
\hline
\end{tabular}




\begin{tabular}{|l|l|}
\hline Facciones & Grupos \\
\hline
\end{tabular}

Fuente: Elaboración propia.

En el cuadro 3 se observa el tipo de organización que se formó durante el conflicto social armado. Desde lo anti-institucional, la acción colectiva de las autodefensas se transformó en una organización regulada, incluyente e impersonal, cuando se transformó en una policía armada rural, sobre todo, porque en la esfera de lo institucional, Los Caballeros Templarios, junto con sus aliados que fueron algunas policías locales y algunos funcionarios del gobierno de Michoacán, establecieron relaciones regidas por la arbitrariedad, lo excluyente y la lealtad personal.

El anterior proceder metodológico ha sido posible porque la opinión pública se ha expresado en los medios masivos impresos, que son el vehículo de la esfera civil, donde los discursos y narraciones de los actores oscilan entre generalidades y abstracciones (ideales), pero también sobre situaciones concretas (particulares) que le confieren significado social a los comportamientos colectivos o individuales, al considerarse como auténticos o inauténticos, como creíbles o no para los otros que configuran audiencias (ALEXANDER, 2006, 44).

Por otro lado, la narrativa periodística del evento interpretado se ha convertido en un discurso cuya característica es un acceso diferenciado de grupos o individuos al mismo debido a que los medios de comunicación los difunden de manera masiva, por tal motivo, configuran puntos de vista diversos sobre un tipo de acontecimiento, involucrando, principalmente, a sus protagonistas, que también se han transformado en las fuentes primarias de información de los periodistas (TORRE-CANTALAPIEDRA, 2018, 2002). Desde ésa perspectiva, este estudio analizó la cobertura que hicieron los siguientes periódicos que tienen, por un lado, una cobertura nacional como El Universal, La Jornada, El País, así como la revista Proceso, por otro lado, como rasgo esencial mostraron las narrativas emitidas por los principales protagonistas del conflicto social. Ahora bien, la cantidad de notas fue cercana a 50 más otras 20 que se recuperaron de fuentes periodísticas aparecidas en sitios de internet, donde había opiniones de analistas sobre el hecho, sin embargo, no contenían las expresiones de los propios protagonistas. Pero esto permitió construir interpretaciones sobre la manera en que el evento fue visualizado por los no participantes, considerados como audiencias, que expresaron su apoyo o condena, su legitimidad o ilegitimidad, y hasta su legalidad o ilegalidad.

Pero la legalidad o ilegalidad como narrativa o discurso se manifiesta a través de la acción social de los protagonistas articulada, por ejemplo, a las creencias o valores como la justicia o injusticia o lo legítimo o ilegítimo, o con lo permitido o lo prohibido. En este sentido, sus motivos pueden estar provocados por la manipulación de la norma, lo que ha servido para mostrar su debilidad ante una 
situación de inseguridad social creada por la violencia criminal o como una ley que se encuentra alejada de los conflictos de la vida social, perdiendo su utilidad y, en consecuencia, no tiene capacidad regulatoria. O también como una manera de encubrir decisiones arbitrarias del poder político y económico (EWICK y SILBEY, 1998). Sin embargo, lo que Ewick y Cavicchi (2005, 556-565) llaman hecho legal, en el caso mexicano, existe como una relación ambigua, es decir, no hay una correspondencia directa entre la norma y las prácticas sociales debido a la existencia de un Estado en las sombras (GLEDHILL, 2016, 145-146). En otras palabras, un Estado que ha configurado un sistema de impunidad vinculado a las economías ilegales, y en la actualidad, a las economías criminales, donde la violencia ejercida por los criminales ha estado protegida en el plano regional por los agentes estatales, políticos y por el sistema de seguridad pública local. Una violencia criminal que en el territorio rural de Tierra Caliente, por ejemplo, esta aliada también con empresas privadas mineras y energéticas, que buscan despojar a las comunidades de su patrimonio (GLEDHILL, 2016, 224-225). En suma, la ley como discurso, en el caso de la violencia colectiva que se interpretó, se expresó en el lenguaje de algunos agentes sociales y articulistas de prensa como el prohibir la presencia de grupos armados en la región de Tierra Caliente porque quienes deberían de estar armados legalmente eran sólo las fuerzas de seguridad. Pero dentro de la narrativa binaria se debe de considerar que el discurso que tiene sólo como referencia la ley sólo adquiere su sentido particular cuando se le liga con el discurso que lo niega. Por ejemplo, los líderes de las autodefensas armadas no apelaron a la ley para justificar su enfrentamiento con el grupo de criminales, llamado Los Caballeros Templarios, sino a que los agentes estatales eran incapaces de garantizar la vida y el patrimonio de los que integraban las diferentes comunidades. Tampoco la intervención en el conflicto regional por parte del gobierno federal (Enrique Peña Nieto, 2012-2018) tuvo como referencia la norma o ley porque fue parte de un Estado articulado con las economías ilegales, que crea posteriormente acuerdos como leyes para transformar a las autodefensas en guardias rurales, registrando ante la Secretaría de la Defensa Nacional sus armas y otorgándoles, al mismo tiempo, uniformes. En consecuencia, la ley es una excepción pero como discurso puede entenderse sólo a través de los valores civiles compartidos grupalmente, pero su sentido se logra insisto cuando existe el discurso que los niega.

\section{La narrativa binaria de las autodefensas}

El 24 de febrero de $2013^{11}$, Hipólito Mora vecino del poblado conocido como la Ruana, acudió a la plaza principal a una reunión para expresarle a los asistentes: "Señores, los invité porque ustedes

\footnotetext{
${ }^{11}$ Ese día es la festividad cívica conocida como el día de la Bandera Nacional. Para una visión estructuralista su significado se relacionaría con la reproducción de la dominación del Estado mexicano. Pero tal vez, la reunión fue
} 
saben cómo nos tienen Los Caballeros Templarios no nos dejan trabajar ya, les están quitando el bocado a nuestras familias. El que tenga valor para defender sus derechos, sus familias y sacar a Los Caballeros Templarios, brínquenle para acá-Y qué brincan todos-recuerda emocionado-muchísima gente. Que gusto me dieron. Vale la pena pensé” (MAERKER, 2014a, 22).

En este caso, Hipólito Mora comenzó a construir una narrativa binaria que justificaba la organización de una rebelión armada contra la existencia de los métodos de explotación y expoliación de Los Caballeros Templarios, usados para quedarse con parte de las ganancias de los negocios privados, derivados de la siembra de limones, melones, aguacates, lo que estaba acompañado de otros beneficios monetarios, producto del tráfico de drogas (MALDONADO, 2014, 155).

Pero esa narrativa particular fue interpretada a través del discurso de la inseguridad pública, que se ha caracterizado por las palabras clasificatorias, presentes en las instituciones de comunicación: sicario, cártel, levantón, halcón, jefe de plaza, lugarteniente, operador financiero (ESCALANTE, 2012, 40-42).

Otra interpretación como hecho narrativo del evento sucedido en La Ruana se basó en la creencia de que había aparecido en tierra caliente una guerra de pobres, según Luis Prados (2013), en un pueblo dedicado al cultivo de limón: "una guerra de pobres en la que solo existe una certeza: en esta zona del país, Tierra caliente en Michoacán, y no es la única, el Estado mexicano no existe”. Esta última afirmación reforzaba la narrativa compartida por algunos académicos mencionados: la inseguridad pública es resultado de la ausencia de gobierno o Estado en diversas regiones de México.

Por tal motivo, el conflicto como hecho violento armado, fue también narrado como consecuencia de un Estado débil, que no podía garantizar la seguridad de vida y propiedades de los pobladores, lo que había reforzado, al mismo tiempo, la representación social sobre la inseguridad pública, que la describe como resultado de la supuesta existencia de un Estado con una función punitiva endeble para castigar a los delincuentes o en el último de los casos porque se ha aliado con los delincuentes a través de las policías locales.

Por otro lado, en la entrada del poblado vecino llamado Buena Vista-Tomatlán, las autodefensas habían colocado una pancarta donde se leía: "Bienvenidos al pueblo Buenavista, libre de cuotas (...pagos ilegales) y de Caballeros Templarios”. Esto muestra, insisto, que fue una rebelión de los

convocada por el dueño de sembradíos de limones y ganado (Hipólito Mora) por ser un día de descanso o de asueto para los vecinos de la comunidad de La Ruana. 
pobladores contra los métodos de acumulación ilegales establecidos por Los Caballeros Templarios y que fueron clasificados en la narrativa del gobierno mexicano como delincuencia organizada ${ }^{12}$.

Por su parte, Hipólito Mora se presentó como un líder local mediante la reafirmación del valor de la lealtad: "Servando Gómez Martínez alías La Tuta (...el principal líder de Los Caballeros Templarios) ofreció por mi cabeza 2 millones de pesos (...y el alcalde de la ciudad de Apatzingán que fue convertida en el refugio principal de Los Caballeros Templarios) ofreció 50 kilos de ice (cristal de coca) de recompensa por (...mi) captura (...) uno de los jefes de plaza (...continúo narrando), Dionisio Loya Plancarte alias El Tío (...utilizando) un video en YouTube, (...me) ofreció un pacto de paz y civilidad para evitar más muertes de inocentes y hogares enlutados. Si no llegamos a un acuerdo, le reto a un duelo a muerte (...y se despidió diciendo) siempre a sus órdenes” (PRADOS, 2013).

Pero en la narrativa de Hipólito Mora los culpables en la creación del escenario de violencia regional eran las autoridades y policías municipales, transformadas en aliados de Los Caballeros Templarios, pero también el gobernador de Michoacán, incluyendo al entonces presidente mexicano Enrique Peña Nieto ("no hacían nada para cambiar la situación”).

Por otro lado, en el municipio de Tepalcatepec, se construyó un liderazgo de las autodefensas a través del médico José Manuel Mireles, cuyo motivo de su rebelión la expresó así: "su autodefensa nació para proteger a Tepalcatepec de la violencia y de las extorsiones de Los Templarios (y denunció más tarde en una entrevista que concedió a un noticiero de la estación de radio llamada Radio Fórmula) que Nazario Moreno (...alias El Chayo y fundador de La Familia Michoacana, antecedente de Los Caballeros Templarios) no murió en 2010 (...como lo anunció el entonces presidente Felipe Calderón Hinojosa). Esta vivo. Si no, pregúntele al gobernador de Michoacán, que estuvo en el sepelio de su papá (del padre de Moreno) el miércoles pasado porque él (Jesús Reyna...el gobernador interino que asumió funciones cuando el gobernador Fausto Vallejo pidió licencia por motivos de salud) también es Templario. Su esposa es hermana de la esposa de La Tuta (...) Estuvieron todas las cabezas visibles del crimen organizado en el estado" (DE LLANO, 2013).

A diferencia de la narrativa de Hipólito Mora, la de José Manuel Mireles apareció desde un inicio en las redes sociales y a través de un video en YouTube, expresando los motivos de su levantamiento en armas y que fue para destruir el método de extorsión de Los Caballeros Templarios:

\footnotetext{
${ }^{12}$ La Ley Federal Contra la Delincuencia Organizada de 1996, reformada en 2011, definió a la delincuencia organizada como la unión de tres o más personas que se organizan para realizar de manera permanente y reiterada, conductas que por sí o unidas a otras, tienen como fin o resultado algunos delitos y dichas personas serán sancionadas como parte de la delincuencia organizada (DIARIO OFICIAL DE LA FEDERACIÓN, 2011).
} 
"Una cuota por cada vaca que vendían, otra por cada kilo de carne vendida, otra por cada kilo de tortilla y reaccionaron (las autodefensas) cuando comenzaron a violar a sus hijas" (CHOUZA, 2013).

De este modo, la seguridad pública, como un hecho social, dependía más de la existencia de hombres armados de la propia localidad, que disputaban el uso de la violencia con los sicarios de Los Caballeros Templarios, cuya fuerza era la base de su sistema de cobro de cuotas ilegales. Por tal motivo, una profesora de Tepalcatepec dijo: "Durante dos meses, los sicarios me esperaban en la puerta de mi casa y cada 15 días (...tenía que pagar una cuota)" (CHOUZA, 2013).

Por otro lado, en el conflicto armado, el líder de Los Caballeros Templarios (Servando Gómez Martínez, La Tuta) construyó su propia narrativa para interpretarlo, usando videos como hechos comunicativos de sus intenciones o motivos, expresando su intención de dejar las armas si el gobierno federal, estatal y municipal, restablecía el estado de derecho que garantizara la paz de los michoacanos.

En consecuencia, la violencia la interpretaba La Tuta como resultado de una falta de un acuerdo negociado por todos los involucrados y acusó a los líderes de las autodefensas “(...de pertenecer) a bandas criminales ligadas a los cárteles de Los Zetas o al grupo denominado Jalisco nueva generación, que tienen como propósito (...) desarticular a Los Caballeros Templarios" (MÉNDEZ, 2013).

Su narrativa, desde un punto de vista general, era para deslegitimar la lucha armada de las autodefensas contra los grupos de narcotraficantes, clasificándolas como un grupo que apoyaba a organizaciones de narcos enemigas de Los Caballeros Templarios. En este sentido, desde el discurso de la legalidad jurídica, se reforzó la misma creencia porque las acciones de las autodefensas fueron clasificadas en el universo de la ilegalidad, clasificadas dentro de las actividades del llamado crimen organizado.

Por eso, el secretario de gobierno de Michoacán (Jesús Reyna), posteriormente convertido en gobernador provisional, dijo que en los municipios donde había presencia de autodefensas no se iba a establecer una mesa de diálogo porque eran grupos que operaban en la ilegalidad. Dicha opinión fue compartida por el subsecretario de Prevención y Participación Ciudadana de la Secretaría de Gobernación, Roberto Campa: "No es con grupos violentos enfrentados con otros grupos violentos (como se va a llegar a una solución) sino respetando la ley” (MARTÍNEZ, 2013).

En resumen, el discurso del líder de Los Templarios se orientó más a descalificar a las autodefensas al considerarlos como grupos manipulados por los cárteles rivales; mientras, el discurso gubernamental fue para calificar sus acciones como ilegales. Pero ambos discursos binarios, desde mi perspectiva, legitimaban el uso de la violencia para combatir a las autodefensas. 
La autodefensa encabezada por José Manuel Mireles ${ }^{13}$ en cada localidad ocupada, reproducía el mismo performance como sucedió en el municipio de Churumuco: “(...) entraban 15 camionetas con individuos armados y se convocaba a un mitin que se celebraba en la plaza pública donde Mireles invitaba a las asistentes a organizarse como autodefensas para combatir a Los Caballeros Templarios. Una vez que sucedía eso se colocaban barricadas o puntos de revisión en los accesos (entradas y salidas) al municipio con hombres armados y encargados de ejercer funciones de vigilancia, pero antes se había procedido a desarmar a los policías municipales, acusados de estar al servicio de Los Caballeros Templarios" (MARTÍNEZ ELORRIAGA, 2013).

En el municipio de Tepalcatepec, el día 24 de febrero de 2013, las instalaciones de la Unión Ganadera funcionaron como un escenario para la reunión de los pobladores que se iban a organizar como autodefensas ${ }^{14}$. En sus afueras armaron una barricada, que coincidía con la entrada al poblado, donde un ganadero, un productor de limón y de sorgo, así como otro de mango vigilaban, sólo el productor de mango habló de sus motivos para unirse a la rebelión, que coinciden con las opiniones analizadas, la extorsión o cobro de cuotas ilegales de parte de Los Caballeros Templarios: "Hace un año, él y los productores locales perdieron la cosecha de 2 mil hectáreas de mango porque la docena de empacadoras en (...la ciudad de) Apatzingan que las comercializaban se negaron a recibirla porque el cártel de Los Caballeros Templarios los había amenazado (...y justificaba) Gracias a que se levantaron las defensas comunitarias tenemos el municipio más seguro de todo México, aquí ya está limpio, ya no hay maña (...mafia)" ${ }^{\prime 15}$.

Por su parte, la narrativa del ex vocero del Consejo General de Autodefensas, Estanislao Beltrán (alias Papá Pitufo), fue para justificar una legalidad particular para el movimiento de las autodefensas, ante denuncias de algunos pobladores que las acusaban de haber realizado la detención de presuntos templarios y que en la realidad no lo eran: "Nosotros vamos por la línea legal, todo el que

\footnotetext{
${ }^{13}$ De septiembre a diciembre de 2012, según José Manuel Mireles, médico de profesión, atendió en una clínica de salud local a 40 niñas violadas por miembros de Los Caballeros Templarios. Pero el enojo colectivo contra la violación de niñas en realidad provino de los ganaderos cuando sus hijas comenzaron a sufrir dicho delito (CASTELLANOS, 2014a).

${ }^{14}$ La reunión en la Unión Ganadera de Tepalcatepec, según José Manuel Mireles, inició en la mañana del 24 de febrero con 80 personas y a las 2 de la tarde eran 3 mil y solo estaban armados 70 cazadores: "Todas las armas que traíamos eran las de los clubes de cacería, rifles 22 y escopetas". Agregó: (...Hipólito) Mora y la gente de Tepalcatepec se reunieron a principios de febrero y eligieron como fecha de rebelión el Día de la Bandera" (CASTELLANOS, 2014a). ${ }^{15}$ Los pobladores de Tepalcatepec se coordinaron con los del municipio de Buenavista y de Coalcomán, que se sumó a la autodefensa el 15 de mayo de 2013, conformando un corredor desde donde se expandieron las autodefensas armadas (CASTELLANOS, 2014a).
} 
esté jugan do mal será consignado, y familiares de Los Caballeros Templarios nos difaman cuando a éstos se les detiene" (CASTELLANOS, 2014a).

El principal centro de detención que utilizaron las autodefensas se localizó en el poblado Los Reyes (ciudad habitada por 50 mil habitantes en la meseta indígena purépecha) que había sido un centro de atención para los alcohólicos. Ahí estuvieron detenidos 49 personas pertenecientes a Los Caballeros Templarios, cuya tarea fue la comunicación por radio para informarle a los responsables del control de cada espacio de la localidad sí había presencia policíaca y del ejército: "Eran los ojos y oídos de los criminales".

Pero su narrativa no asumía su culpa por participar en la organización de Los Templarios sino sólo expresaba su arrepentimiento: “(...) el cártel (Los Caballeros Templarios) llegó a sus barrios ofreciéndoles mil 800 pesos a la semana, motos, despensas y cigarros, para que vigilaran desarmados a unidades federales en un horario inicial de ocho horas, que luego les aumentaron a 12 (...pero) los capos no les cumplieron. Que los atemorizaban con atacar a sus familias y no les pagaban. Que a unos les deben hasta seis meses de sueldo (...y uno agregó) Y si perdíamos la radio, la teníamos que pagar. "Nos amarraban", expone una más. "Nos llevaban al cerro y nos golpeaban, agrega otro. "Y sí se nos pasaban las unidades (policiacas o de militares), nos mataban", se escucha" (CASTELLANOS, 2014b). Es decir, en lugar de ser culpables se presentaban en su encierro como víctimas de Los Caballeros Templarios al igual que el resto de los pobladores.

Estos hechos considerados como performances formaron una acción colectiva integrada por lo siguiente: detención de los informantes o halcones que estaban al servicio de los líderes de Los Caballeros Templarios, desarme de los policías municipales que eran acusados de colaborar con el cártel y de poner la seguridad pública local en manos de las autodefensas formadas por los habitantes de los mismos municipios. Mientras, los líderes de las autodefensas y su grupo armado seguían su camino hacia otros municipios donde se había implantado el mecanismo de extorsión de Los Caballeros Templarios ${ }^{16}$.

La necesidad de justificar el origen lícito de las armas usadas por las autodefensas fue a través del discurso de la participación de los principales agentes del desarrollo regional, como lo fueron los empresarios locales-ganaderos y dueños de tierras de siembra de frutos y legumbres de exportación-,

\footnotetext{
${ }^{16}$ Esta manera de actuar se repitió en los municipios que tomó José Manuel Mireles como fueron: Zicuirán, Chauz, La Huacana, Churumuco y Poturo (MARTÍNEZ ELORRIAGAl, 2014).
} 
así como por las aportaciones que hicieron los migrantes michoacanos, radicados en los Estados Unidos $^{17}$.

Pero también se debe de considerar que algunas autodefensas nacieron como guardias comunitarias sobre todo en las localidades de mayoría indígena, antes de $2013^{18}$, eran grupos armados que resguardaban los bienes comunales para evitar su explotación comercial de parte de empresas privadas o de particulares. En esta situación se encontraban las comunidades indígenas de la localidad de Santa María Ostula, municipio de Aquila, donde en 2009, sus policías indígenas fueron disueltas por Los Caballeros Templarios.

Sin embargo, la situación cambió cuando comenzó la expulsión de Los Caballeros Templarios en los municipios de La Ruana y Tepalcatepec, por tal motivo, el 8 de febrero de 2014, siete líderes de la etnia nahua expulsados por Los Caballeros Templarios, y encabezados por el productor de papaya Semeí Verdía ocuparon el pueblo con 40 guardias rurales y celebraron en ése momento una asamblea popular con la asistencia de 1200 personas que aprobaron la permanencia de la autodefensa; mientras, se creaba una policía comunitaria, y aceptaban como su comandante a Semeí Verdía (CASTELLANOS, 2014c).

La integración de más habitantes de tierra caliente a los grupos de autodefensa de Mireles y Mora provocó que una funcionaria del Departamento de Estado de los Estados Unidos dijera que el gobierno de Barak Obama estaba preocupado por los acontecimientos que habían colocado a las comunidades entre el fuego de las organizaciones de narcotraficantes y de las autodefensas: "no está claro si alguno de estos grupos están de verdad interesados en lo que es lo mejor para sus comunidades" (AGENCY FEDERAL PRESS, 2014).

\footnotetext{
${ }^{17}$ En el municipio de Coalcomán, las autodefensas fueron encabezadas por los empresarios de la madera y en el municipio de Los Reyes por un productor de zarzamora. Pero más allá del apoyo otorgado por los migrantes michoacanos radicados en Estados Unidos se trató, según la prensa estadounidense, de michoacanos deportados que “(...) fueron miembros de las pandillas de Los Ángeles o trabajadores de la construcción en Texas (...). O recolectores de manzana del estado de Washington que fueron despedidos (...sin embargo) Édgar Orozco (...) ciudadano estadounidense de 27 años, quien dejó su trabajo en un taller de carrocería en Sacramento para unirse (a las autodefensas) (...fue porque) Los Caballeros Templarios mataron a su tío y a su primo (...) José Manuel Mireles vivió durante varios años en Sacramento y trabajó para la Cruz Roja (...) Luis Antonio Torres González (...fue) vendedor de autos viejos en El Paso (...por eso su alias El Americano)...se unió a la lucha después de que fuera secuestrado en unas vacaciones familiares en Michoacán en octubre de 2012. Sus familiares vendieron sus tierras para pagar (su) rescate de 150 mil pesos" (PARTLOW, 2014).

${ }^{18}$ El Artículo 2 de la Constitución Política Estados Unidos Mexicanos $(2016,2)$ permite a las comunidades indígenas elegir a sus propias autoridades de acuerdo con sus usos y costumbres, en otras palabras, el gobierno mexicano reconoce el derecho a decidir de parte de los pueblos indios sus formas internas de convivencia y organización económica, social, política y cultural.
} 
La declaración de la funcionaria estadounidense influyó en la intervención posterior del gobierno de Enrique Peña en el conflicto michoacano de manera discursiva en el plano internacional. Por ejemplo, en una visita a Canadá rechazó que durante su primer año de gobierno se haya dejado "crecer" a las autodefensas: "De ninguna manera, al contrario, creo que el espacio que nos ha permitido este año de actuación, como las cifras y la estadística claramente lo acreditan (...) hay una disminución real, realmente de los niveles de violencia (...y en Michoacán el) gobierno de la república (...debe) hacerse cargo de la seguridad (...) de aplicar la ley (...la) estrategia no sólo (...es) combatir la inseguridad y a la delincuencia (...) sino (...) la reconstrucción del tejido social y (...) lograr un desarrollo integral en (...la) entidad" (VARGAS, 2014).

En consecuencia, algunos funcionarios del gobierno de Enrique Peña Nieto opinaron en el mismo sentido en eventos internacionales como lo fue en el Foro Liderazgo Turístico Exceltur 2014, celebrado en la ciudad de Madrid (España), donde la entonces secretaria de Turismo (Claudia Ruiz Massieu) dijo: "El tema de Michoacán no es un tema que haya afectado al comportamiento del sector, que creció en el año tanto en ocupación, en llegadas como en gasto y derrama. El tema de Michoacán está siendo atendido de manera puntual por el gobierno de la República en coordinación con el gobierno estatal" (TEJEDA, 2014).

La estrategia de intervención en el conflicto de parte del gobierno de Peña Nieto fue a través de la vía militar, apoyada en los programas de asistencia social en programas de financiamiento de algunos negocios privados familiares, lo que en opinión del periodista Jesús Aranda (2014) daría como resultado la detención de los delincuentes y el fin de la impunidad, favoreciendo el crecimiento del bienestar colectivo. En ese momento se va configurando un discurso general, que identificó la inseguridad pública con el crimen organizado (narcotráfico), y también reforzó la visión de que la inseguridad pública era producto de una doble ausencia del Estado, no impartía justicia penal y no tenía políticas públicas económicas ni sociales regionales.

Al mismo tiempo, se fue materializando el proceso de construcción cultural de la acción armada de las autodefensas en iconos no sólo por la vestimenta (rostros cubiertos o mediante el uso de playeras blancas con la leyenda "autodefensa") sino en los principales líderes como lo fueron José Manuel Mireles e Hipólito Mora (BARTMANSKI y ALEXANDER, 2012, 2-6).

Por tal motivo, su poder icónico les permitió ser vistos como "luchadores" contra la inseguridad pública nacional, causada por el crimen organizado; lo que opacó el discurso oficial que sostenía que la ilegalidad no se combatía desde la ilegalidad, con otras palabras, que las acciones armadas de las autodefensas carecían de una legitimidad basada en las normas o leyes (RAMÍREZ, 2011). 
En este sentido, Arturo Barragán, miembro de las autodefensas, opinó: “José Manuel Mireles es líder y es uno más entre los compañeros de los autodefensas (...) denunció los abusos de los que sus vecinos han sido víctimas (...) hombre dialogante, intermediario entre las autodefensas y el ejército (...) denunció violaciones de mujeres de parte de Los Caballeros Templarios (...invitaba a la prensa) vengan hasta aquí y cuenten la verdad" (CHOUZA, 2014a).

El día 26 de octubre de 2013, en un acto realizado por Mireles, fue calificado por sus seguidores como "heroico" y "simbólico" porque acepto entrar a la ciudad de Apatzingán desarmado porque el ejército no les permitió entrar con sus armas. A pesar de eso, celebró el mitin en la plaza principal, donde estalló una granada, aunque durante 30 minutos pronunció su discurso, invitando a los presentes a formar autodefensas: "Únanse, venimos a estar con ustedes, únanse a este movimiento social empezamos hace ocho meses, queremos exterminar, acabar y expulsar al crimen organizado de todo el estado de Michoacán. Unánse a la marcha por la libertad del estado, únanse a la marcha por la libertad de Apatzingán, es un beneficio de ustedes, de sus familias y de sus hijos, únanse a la marcha por la libertad de Apatzingán" (CHOUZA, 2014a).

Después del discurso, Mireles se refugió en un edificio contiguo a la plaza y empezó un ataque armado de Los Templarios que recibió contestación de parte de las autodefensas, sin embargo, Mireles acordó con el ejército y la policía federal abandonar la ciudad de Apatzingán y regresar escoltado, con sus acompañantes, a su pueblo ${ }^{19}$.

Para el 28 de octubre de 2013, los grupos de autodefensa se habían organizado en el Consejo General de Autodefensas y Comunitarios de Michoacán, lo que facilitó la intervención gubernamental porque se transformó en la única organización aceptada por el gobierno para coordinar las acciones militares del ejército y de las autodefensas contra Los Caballeros Templarios, después de una reunión privada con el entonces procurador General de la República (Jesús Murillo Karam), Mireles, como vocero del Consejo General, informó que habían aceptado la propuesta (CASTELLANOS, 2014a).

La colaboración gubernamental con las autodefensas "contaminó" al movimiento, lo que quedó en evidencia en la siguiente coyuntura: El 4 de enero de 2014, José Manuel Mireles sufrió un accidente en una avioneta que tripulaba, perdiendo protagonismo mediático al ser hospitalizado, y en su función

\footnotetext{
${ }^{19} \mathrm{El} 5$ de enero de 2014, un grupo de pobladores de Apatzingán y con el rostro cubierto bloquearon la carretera Caminos-Apatzingán, cerca de Parácuaro, utilizando 2 autobuses de pasajeros y un camión de carga, como protesta porque desde el día anterior un grupo de autodefensas había ocupado la cabecera municipal de la ciudad, provocando desconfianza y temor cuando detuvieron a 11 policías del municipio. Se sospecha que eran integrantes de Los Caballeros Templarios debido a que Apatzingán se había convertido en el lugar de residencia de varios de sus líderes (MARTÍNEZ ELORRIAGA, 2014).
} 
de vocero fue sustituido por Estanislao Beltrán (Papá Pitufo) quien firmo el 27 de enero de ése año con el gobierno federal un acuerdo para legalizar a las autodefensas como guardias rurales, lo que fue sancionado por un Comisionado (Alfredo Castillo Cervantes), cuya figura fue creada por el presidente Peña Nieto, para dirigir la Comisión de Seguridad y Desarrollo Integral de Michoacán ${ }^{20}$ (FERRER, 2014).

El otro líder principal-que también ejerció un poder icónico- fue Hipólito Mora quien discursivamente comenzó a identificar a Los Caballeros Templarios con el crimen organizado y a las guardias comunitarias las calificaba como "luchadores" contra sus arbitrariedades e ilegalidades que fueron cometidas contra los pueblos de tierra caliente.

Hipólito Mora dijo: "Michoacán (...está) en manos del crimen organizado. Y las guardias comunitarias no se someterían al crimen organizado (...) que han quemado autobuses y camiones en las salidas de los pueblos que controlan las autodefensas. Son Los Templarios. Nosotros somos gente de trabajo, gente productiva" (CALDERÓN, 2014a).

Desde otro punto de vista, la presidenta de organizaciones Michoacanas pro Derechos Humanos, Cristina Cortés Carrillo opinó que las autodefensas se estaban convirtiendo en una “preinsurgencia”, y está situación, le obligó a enviar al Alto Comisionado de la Organización de las Naciones Unidas (ONU) información sobre la gravedad del asunto (CALDERÓN, 2014a).

El tema de las autodefensas fue enfocado como un problema de seguridad nacional por parte del gobierno Federal, y en un evento celebrado en la capital de Michoacán (Morelia), donde participó como orador principal el secretario de Gobernación Miguel Ángel Osorio Chong, dijo que en la zona (donde había autodefensas) tenía más de una década de inseguridad, pero emplazaba a las autodefensas a regresar a sus lugares de origen porque el Estado (mexicano) se haría cargo de la seguridad de las comunidades en conflicto. Pero como estaba acompañado del gobernador Fausto Vallejo Figueroa (cuyas ausencias del cargo fueron frecuentes por una enfermedad) no le quedo más opción que apoyar la afirmación del gobierno Federal y condenó la violencia de las autodefensas, que habían enlutado hogares (se solidarizaba con las familias de las víctimas) y a partir de ese día empezaría a despachar “de manera recurrente desde Apatzingán”.

Al mismo tiempo, Osorio Chong invitó también a los civiles a proporcionar información que tuvieran sobre los criminales, lo que se debería de acompañarse de la entrega de sus armas porque no

\footnotetext{
${ }^{20} \mathrm{La}$ fecha límite del desarme de todos los grupos de las autodefensas sería el 10 de mayo de 2015. El comisionado en un primer momento quería que las autodefensas se transformaran en grupos de defensas rurales dependientes del Ejército mexicano, después optó por la creación de una fuerza rural estatal.
} 
se toleraría que alguien usara armas sin estar facultado legalmente, y puso como logro, la ocupación del ejército mexicano del Puerto de Lázaro Cárdenas (CALDERÓN, 2014b).

Por otro lado, Mireles recuperado del accidente y sin su puesto de vocero del Consejo, usó un video difundido en las redes sociales para pedirles a las autodefensas no aceptar la propuesta de desarme del gobierno Federal, lo que también fue transmitido en un noticiero nocturno, con mayor audiencia nacional de la empresa de la televisión privada (Televisa), horas más tarde se contradijo utilizando un segundo video, donde apoyaba el rechazo previo de algunos líderes de las autodefensas a la oferta gubernamental del desarme, condicionada a la detención de todos los líderes del narco de la región. En ése segundo video, colocado en el sitio de YouTube, Mireles cambiaba de opinión y condicionaba el desarme al arresto de la dirigencia de Los Caballeros Templarios. Fue demasiado tarde. En las cuentas de las redes sociales de las autodefensas circuló el mensaje de que no se le haría caso a Mireles en lo relacionado con el desarme y el nuevo vocero del Consejo (Estanislao Beltrán, Papá Pitufo) en una entrevista radiofónica dijo: “(...Los Caballeros Templarios eran) los que habían ocasionado los levantones [secuestros en el argot criminal]" (Calderón, 2014c). Por tal motivo, una vez que les entregaran a Nazario Moreno (El Chayo), Servando Gómez (La Tuta) y a Enrique Plancarte (El Quique) dejarían las armas ${ }^{21}$.

Los motivos del gobierno Federal para convertir a las autodefensas en policías rurales no sólo fueron los de rehacer su control punitivo en la región; sino, el reforzar la creencia social acerca de que la inseguridad nacional es consecuencia de la expansión territorial del llamado crimen organizado (CHIGNOLA, 2016,169-173).

Por eso, la autonomía de las acciones de las autodefensas fue por la existencia de una esfera civil, que favoreció la difusión de su discurso comunicativo, justificando su acción armada contra el sistema de expoliación administrado por Los Caballeros Templarios.

Pero esa acción colectiva, autónoma y armada, sufrió la intervención del gobierno Federal, cuando sus líderes comenzaron a justificar sus acciones mediante el discurso binario de la inseguridad pública. En otras palabras, lo compartieron ambas partes y la solución viable sería a través de la fuerza punitiva, fortalecida localmente al transformarse en policías rurales.

\footnotetext{
${ }^{21}$ Esta nueva situación provocó enfrentamientos entre las autodefensas y el ejército en la localidad de Antúnez donde murieron dos pobladores y algunos dijeron: "Los muertos sólo eran guardias comunitarias y no iban armados" (CALDERÓN, 2014d). Estanislao Beltrán, el nuevo portavoz del Consejo, afirmaba que eran 4 en un programa de noticias de MVS, el periódico Reforma informaba que habían muerto 12 personas y en un video colocado en YouTube se observaba en Antúnez el enfrentamiento armado entre autodefensas y militares.
} 


\section{El discurso binario de autonomía y colonización de la acción social ${ }^{22}$}

Los usos y costumbres de las comunidades indígenas mexicanas han sido la base de una esfera civil que ha reproducido una solidaridad particular, lo que le ha conferido su autonomía (ALEXANDER, 2010, 10), establecida legalmente en el Artículo 2 de la Constitución Política Estados Unidos Mexicanos. Esta legalidad funcionó como base de la opinión pública que consideró a las autodefensas como guardias comunitarias legales. Pero olvidaban que algunos de las autodefensas se habían integrado, en algunos casos, por mestizos que no se regían por usos y costumbres indígenas (NOTICIARIOS TELEVISA, 2013).

Por otro lado, otros consideraban la autonomía organizativa de las autodefensas como un medio para ejecutar un enfrentamiento armado entre los vecinos de tierra caliente porque "Michoacán representa (...ba) la suma de todos los fracasos del Estado mexicano para enfrentar al crimen organizado (...las) guardias autoarmadas (...hacían) el honor a la tradición local de saberse huérfanos de Estado, a la inclinación (...de) hacerse justicia por mano propia” (ZEPEDA, 2014).

En este sentido, el historiador Enrique Krauze (2014), interpretó la aparición de las autodefensas de tierra caliente como una consecuencia de la violencia criminal generalizada en el país debido a que la democracia tuvo un efecto centrífugo, no sólo limitó el poder autoritario presidencial, sino, que favoreció la autonomía de los poderes criminales aliados con los políticos locales y las policías corruptas. "Comenzó la guerra civil entre los carteles y la guerra entre ellos y el Estado". Sin embargo, valora como una acción positiva que el gobierno de Peña Nieto haya ocupado el territorio de tierra caliente mediante las fuerzas federales (policía y ejército) y también el plan de incorporación de las autodefensas como fuerzas de vigilantes dentro del ámbito de la esfera legal.

La autonomía de la acción armada de las autodefensas fue criticada con el argumento de que la función punitiva era exclusiva del Estado mexicano, así opinó el ex presidente colombiano Álvaro Uribe: "Cuando las instituciones del Estado no operan a tiempo, surgen violencias y contraviolencias, y hay que enfrentarlas con igual severidad y a tiempo. Es muy grave que la función del Estado sea reemplazada por una organización privada, es muy grave" (GUARDIOLA, 2013).

Por su parte, el director-José Miguel Vivanco-de las Américas de Human Rights Watch (HRW) opinó que "la débil aplicación de la ley" generó la aparición de las autodefensas porque las fuerzas de seguridad han participado en las desapariciones forzadas desde el sexenio del ex presidente Felipe

\footnotetext{
${ }^{22}$ El significado de colonización no se deriva del otorgado por Habermas (1999); sino, en el sentido de Alexander $(2013,594)$ que hace referencia a la dominación de una esfera civil sobre otra y que afecta su autonomía y bloquea el monopolio de beneficios para las élites de las mismas, imponiendo sus códigos y regulaciones.
} 
Calderón (2006-2012), quien decretó la llamada "Guerra contra las drogas", multiplicando la impunidad por el aumento de las violaciones de los derechos humanos de parte del ejército (OTERO, 2014).

En ése sentido, José Antonio Ortega Sánchez (presidente del Consejo Ciudadano para la Seguridad Pública y la Justicia Penal) compartió la misma opinión: las autodefensas nacieron debido a que las autoridades eran incapaces de atender las problemáticas existentes en materia de seguridad pública (DELGADO, 2013).

Pero también con base en uno de los videos que puso La Tuta en las redes sociales, según Ricardo Alemán (2014), se podía observar que las autodefensas carecían de autonomía debido a que unos de sus líderes “Antonio Torres González-moteado como El Americano-, no sólo (...recibía) instrucciones de La Tuta, sino que se despide con un elocuente “ $¡$ Como usted diga $;$ ”". Esta evidencia mediática se utilizó para poner en duda la supuesta "autonomía" de las autodefensas de tierra caliente con respecto al crimen organizado regional.

Los videos que usaba el líder de Los Caballeros Templarios (La Tuta) mostraron también que las autoridades michoacanas estaban ligadas a sus intereses: “( ...) todos vimos al secretario de Gobierno (del gobernador ausente por enfermedad Fausto Vallejo) recibiendo instrucciones de Servando Gómez, La Tuta, líder de Los Caballeros Templarios (...y) fotografías (...que exhibían al hijo del gobernador) con el mismo delincuente" (MAERKER, 2014b).

En suma, la autonomía de la organización armada de las autodefensas, de acuerdo con el discurso binario usado, era por la ausencia de seguridad pública, provocada por la debilidad del Estado (Sicilia, 2014) o también por el “(...) hartazgo social (...debido al) incremento del pago de piso y de la extorsión", según el ex gobernador de la entidad Leonel Godoy (MICHEL, 2014). Pero su “contaminación" también fue resultado de que algunos de los miembros de las autodefensas habían sido colaboradores de Los Caballeros Templarios.

El discurso que relacionó la crisis de inseguridad en Michoacán con el nacimiento de las autodefensas también fue usado para justificar la intervención policiaca y militar en las comunidades, lo cual debería de tener los efectos esperados (proporcionar seguridad pública); pero si se acompañaba de programas de desarrollo económico y social, según Antonio Mazzitelli, representante de la Ofícina Regional de la ONU contra la Droga y el Delito para México (CAMACHO, 2014).

El discurso binario analizado establecía que la violencia era consecuencia del funcionamiento del sistema económico (neoliberal) y de la debilidad del orden legal, lo que había creado un Estado 
ausente y sin capacidad de regulación para evitar la expansión de las actividades ilegales y relacionadas con el tráfico de drogas y basadas en los métodos de extorsión.

Entonces, la solución, de acuerdo con el discurso que compartía el punto de vista gubernamental, estaría en que la presencia del Estado fuera a través de las fuerzas federales, consideradas como garantes del orden legal, acompañada de programas de ayuda social, que evitaran la integración de más pobladores al sistema ilegal del tráfico de drogas.

Las críticas discursivas contra el gobierno mexicano oscilaron entre la debilidad del Estado, que no podía aplicar la ley, y en su respuesta tardía que tuvo a través de las fuerzas federales, que no habían evitado el surgimiento de las autodefensas, por tal motivo, la solución sería el colocarlas en el plano de la legalidad (como policía rural), pero actuando, aunque sea contradictorio, desde la ilegalidad a través de un comisionado, que fue nombrado por el presidente Enrique Peña Nieto, y que realizó funciones de seguridad pública al margen de la autoridad legal de Michoacán (LEMUS, 2015) ${ }^{23}$.

Por ello, la esfera civil de las autodefensas fue una esfera de solidaridad particular, que sufrió cambios o transformaciones, por la intervención del gobierno Federal y también por los ex colaboradores de Los Caballeros Templarios que se sumaron a sus filas al ser perdonados por la misma comunidad (De MAULEÓN, 2014: 15-21).

De este modo, la existencia de la esfera de solidaridad creada por las autodefensas no se puede entender como una armonía lograda por la intervención de otras esferas, como por ejemplo las que forman la sociedad civil y la gubernamental, sino como consecuencia de su pluralidad, que en el caso mexicano, no se orientaron por los valores democráticos porque se compartió más el carácter excluyente de la demanda de justicia penal, caracterizada por una solución punitiva, ante la ausencia de su regulación legal, para proteger de manera discrecional intereses particulares (ALEXANDER, 2013, 594).

\section{Las autodefensas como policías rurales}

El comisionado Alfredo Castillo Cervantes, que presidió la Comisión para la Seguridad y el Desarrollo Integral de Michoacán, dijo que su tarea principal era desarmar a los grupos de autodefensa y establecer, con apoyo del gobierno federal de Enrique Peña Nieto, los programas oficiales de asistencia social ${ }^{24}$.

\footnotetext{
${ }^{23}$ Por ejemplo, el ex gobernador Leonel Godoy opinó que nombrar un comisionado para solucionar el problema de las autodefensas era jurídicamente anticonstitucional, violaba la soberanía del estado de Michoacán, dejaba de lado las funciones de seguridad que debería de ejercer el gobernador (MICHEL, 2014).

${ }^{24}$ Castillo Cervantes dijo en una entrevista periodística: "Los líderes (...de las autodefensas), representan intereses legítimos (...en las) reuniones nos piden rellenos sanitarios, computadoras, procesadoras de limón, una escuela
} 
Mientras, el 27 de enero de 2014, el comisionado anunció que las autodefensas se institucionalizarían en el momento en que se incorporaran a los cuerpos de defensa rurales del ejército mexicano. Meses después (el 16 de mayo de 2014) corrigió y anunció que las autodefensas formarían parte de la fuerza rural estatal.

De acuerdo con el comisionado, la opción para su transformación en guardias rurales fue por la existencia de una figura jurídica que data del siglo XIX en el espacio rural, pero ahora las autodefensas necesitaban capacitación y adiestramiento, y este era el motivo del porqué debían de empadronarse y declarar el número y tipo de armas de fuego de su propiedad (CAMARENA, 2014).

La firma de un acuerdo entre el gobierno Federal, a través del comisionado, con los líderes de las autodefensas, cuando José Manuel Mireles (no era el vocero del Consejo por su convalecencia en el hospital como consecuencia del accidente aéreo que sufrió), provocó que el nuevo vocero Papá Pitufo dijera: "Hemos hecho público el nombramiento porque las declaraciones del doctor Mireles no están autorizadas por el consejo ciudadano, son a título personal" (CHOUZA, 2014b).

La desautorización fue porque Mireles calificó de "teatro" el acuerdo firmado por los líderes de las autodefensas y el gobierno federal y estatal que sirvió para legalizar a las autodefensas: "El pacto es político. No tiene nada que ver con la realidad. La prueba está en que al día siguiente mis compañeros tomaron los municipios de Los Reyes y Peribán y van a seguir avanzando" (CHOUZA, 2014b).

Pero Estanislao Beltrán (Papá Pitufo) insistía en que ya se estaban dando de alta para convertirse en defensas rurales. Este acuerdo, el 10 de mayo de 2014, cambio el escenario de las autodefensas en el municipio de Tepalcatepec, uno de los lugares donde inició el levantamiento armado de Mireles, cuando el comisionado hizo oficial la creación de las fuerzas rurales: "Hoy los que representan al Estado son ustedes y de ustedes depende que en un futuro, llámese un mes o 15 meses, no tengamos otras personas solicitando la presencia del Estado (subrayado mío) porque consideren que ustedes no están representando a las comunidades y familias" (MUEDANO, 2014a). Así, supuestamente se evitaría la debilidad de los cuerpos de seguridad, según Castillo Cervantes, provocada por la infiltración de los miembros del crimen organizado.

En la ceremonia de la transformación de las autodefensas en policías rurales, Estanislao Beltrán dijo: "Yo creo que con esto le damos la legalidad. Nosotros ya podemos traer un arma y eso es lo importante, no vamos a andar de ilegales y que en cualquier momento nos atrapen y nos lleven a la

secundaria, cuatro doctores (...) no creo que sean demandas de una organización que representa peligro...En cuanto a las armas, hay que distinguir zonas urbanas de las rurales, en estas la gente desde hace muchos ha estado armada, para proteger sus fincas, para proteger su ganado, para protegerse de animales. No es que anden con esas armas en centros comerciales como algunos creen. Para ellos es cosa de su cotidianidad" (CAMARENA, 2014). 
cárcel por estar armados. Estamos en la legalidad y con ello ya tenemos un compromiso, somos parte del gobierno" (MUEDANO, 2014a).

Mientras, José Manuel Mireles, quien ya no era vocero del Consejo de las Autodefensas, en una charla que tuvo con estudiantes y con organizaciones civiles, en un escenario urbano (la ciudad de México), dentro del auditorio de la Universidad Autónoma de la Ciudad de México (UACM), criticó la transformación de las autodefensas en fuerzas rurales porque era una estupidez debido a que entre sus miembros había integrantes del crimen organizado (MUEDANO, 2014b).

Pero ahora se consideraba un luchador social, lo que dijo en el momento en que se le preguntó del porqué de su destitución como vocero de las autodefensas: "Vocero es alguien que se contrata. Los luchadores sociales no somos voceros de nadie, porque como líder nadie me puede quitar una posición que tampoco nadie me dio" (MUEDANO, 2014b).

Antes, de su viaje a la ciudad de México, en el municipio donde era oriundo (Tepalcatepec), dijo que se sentía traicionado por el gobierno Federal y por algunos miembros de las autodefensas, sin embargo, seguiría con su movimiento de autodefensas para convertirlo en nacional: "Vamos a hacer una convención nacional pronto, van a salir las convocatorias (...) Se buscan dos objetivos, los mismos que hemos peleado en Michoacán (...): seguridad pública e impartición de justicia” (MUEDANO, 2014c).

El no aceptar el nuevo escenario creado por el acuerdo firmado, provocó el surgimiento de un discurso binario que lo presentaba como un "rebelde" que no aceptaba la legalidad, emitido por el comisionado Castillo y Papá Pitufo. Castillo, por ejemplo, dijo que Mireles era investigado por su presunta culpabilidad en el homicidio de cinco personas, la prueba era una foto reproducida en la prensa escrita donde se ve a Mireles sujetando la cabeza de un hombre muerto por balas. Mientras, que Papá Pitufo decía que a Mireles ni en Tepalcatepec lo querían.

Pero al no aceptar el desarme y declarar que algunos de los integrantes de la fuerza rural tenían nexos con el crimen organizado y al formar un nuevo grupo de autodefensa armada en el poblado La Mira (ubicado en el municipio de Lázaro Cárdenas, cercano al Océano Pacífico), le significó su detención y encarcelamiento el 27 de junio de 2014. Su abogada Thalía Vázquez Alatorre opinó: "la detención de Mireles es un golpe durísimo al pueblo de México (...) en este país se usa el poder judicial para resolver asuntos políticos" (CHOUZA, 2014b).

En consecuencia, la creación de un nuevo escenario gubernamental mediante acuerdos clasificados como legales han provocado que los participantes, espectadores, y los que han sufrido las consecuencias de sus acciones de fuerza, reconozcan nuevas formas de organización a través de otras 
narrativas alejadas de los valores o ideales vinculados con la democracia, considerada como un orden legal que ha definido a la ciudadanía a través de los derechos (DURAND, 2010).

El uso de la fuerza como violencia tanto de las autodefensas, Los Caballeros Templarios y el gobierno federal, generó un discurso binario de amigo/enemigo que encontró una justificación en la representación colectiva construida sobre la creencia que define la inseguridad pública como un problema de delincuencia organizada, relacionada más con las actividades del narcotráfico. Por tal motivo, nadie se hizo responsable de sus actos vividos por otros como agravios y como muerte, lo que acabó por fabricar un nuevo orden social sostenido por la impunidad y el castigo de quienes no lo aceptan o buscan transformarlo de nuevo mediante el uso de la fuerza (NEOCLEOUS, 2010).

\section{Reflexiones finales}

El performance de las autodefensas de tierra caliente, expresado como narración binaria, mostró las peculiaridades de una rebelión rural armada contra el dominio ejercido por Los Caballeros Templarios, cuya autenticidad se fortaleció través de la representación social nacional que le atribuía al crimen organizado la inseguridad pública de México.

Dicha representación social también fue utilizada para legitimar la intervención estatal en el conflicto, cuya "solución" fue la transformación de las autodefensas en una policía rural, es decir, su legalización. La legalización permitió también la intervención de otros actores, como los partidos políticos, para intentar convertir a algunos de los líderes de las autodefensas en candidatos a puestos de elección popular, aprovechando su apoyo popular de algunas comunidades locales (MARTÍNEZ ELORRIAGA, 2015).

Pero, la lucha simbólica, en realidad, no sólo fue para mostrar la credibilidad de las acciones armadas de las autodefensas, cuyos líderes posteriormente mostraron su división, en el momento en que algunos buscaron ser reconocidos como auténticos portavoces de la lucha contra el crimen organizado y otros para conservar, a su vez, su presencia regional mediante la legalidad que el gobierno Federal les otorgó cuando aceptaron realizar tareas de seguridad en sus pueblos o comunidades, lo que significó que su función punitiva les fue conferida desde el Estado, ante una situación donde la existencia de policías municipales fueron considerados como parte del sistema de seguridad de los negocios privados del narcotráfico. 


\title{
The narrative performance of the violence of the self-defense of "tierra caliente" Mexico
}

\begin{abstract}
The purpose of this article is to interpret through the binary narrative (goods/bads) appeared in the press about "tierra caliente" self-defense groups (Michoacán) in a scenario of armed conflicto. Where the motives of the main protagonists were expressed as reproducing the social representation of public insecurity, identified with the illegal activities of the different groups of drug traffickers, without considering that their violence is part of a particular method of dispossession legitimized by the weakness of the civil values of inclusion and solidarity. In addition, in the armed conflicto, the illegality prevailed, which was articulated with exclusionary values where human life was not visualized as a human right. At the same time, the idea that regional public insecurity was the result of the multiplication of criminal groups in complicity or not with local authorities was strengthened. Meanwhile, the perspective used was based on the proposal derived from point of view of the cultural sociology of Jeffrey Alexander.
\end{abstract}

Keywords: Binary narration, motives, violence, drug trafficking, performance.

\section{Bibliografía}

ABRIL, Jean-Calude (2004). "Las representaciones sociales: Aspectos teóricos”. En Jean-Claude Abric (Dir.). Prácticas sociales y representaciones. México: Ediciones Coyoacán.

AGENCY FEDERAL PRESS (2014). ““"Extremadamente preocupantes” los sucesos en Michoacán:

EU”. Visita $\quad$ el 4 de $\quad$ abril $\quad$ de 2016

http://www.joranda.unam.mx/ultimas/2014/01/15/201 cextremadamente-preocupante201d-lossucesos-en-michoacan-eu-4000.html

ALEMÁN, Ricardo (2014). "Se derrumba la farsa". Visita el 25 de mayo de 2016 http://www.eluniversalmas.com.mx/columnas/2014/08/108501.php

ALEXANDER, Jeffrey (2013). "Real Civil Societies: Dilemmas of Institutionalization”. En Kivisto, Peter (Editor). Social Theory. Roots \& Branches. Oxford: Oxford University Press, pp. 588-601.

ALEXANDER, Jeffrey (2010). The performance of politics. Obama's victory and the democratic struggle for power. Oxford. Oxford University Press.

ALEXANDER, Jeffrey (2006). The civil sphere. Oxford: Oxford University Press.

ARANDA, Jesús (2014). "Milicia y justicia/Labor cosmética para combatir la violencia en Michoacán”. Visita el 24 de enero de 2016 http://www.jornada.unam.mx/ultimas/2014/01/24/miliciay-justicia-la-labor-cosmetica-para-combatir-la-violencia-en-michoacan-3809.html 
ASTORGA, Luis (2015). “¿Qué querían que hiciera?” Inseguridad y delincuencia organizada en el gobierno de Felipe calderón. México: Grijalbo.

BARTMANSKI, Dominik y ALEXANDER, Jeffrey (2012). "Materiality and meaning in social life: Toward an iconic turn in cultural sociology”. En Alexander, Jeffrey, Bartmanski, Dominik y Giesen, Bernhard (Editores). Iconic Power. Materiality and meaning in social life. New York: Palgrave macmillan.

BAYÓN, María (2015). La integración excluyente. Experiencias discursos y representaciones de la pobreza urbana en México. México: UNAM/IIS/Bonilla Artigas Editores.

BECK, Ulrich (2006). La sociedad del riesgo global. Madrid: Siglo XXI.

BUSCAGLIA, Edgardo (2015). Vacios de poder en México. México: Proceso/Grijalbo.

BOURDIEU, Pierre (2002). Lección sobre la lección. Barcelona: Anagrama.

CALDERÓN, Verónica (2014a). "Peña Nieto afronta el conflicto más grave de México en los últimos 20 años". Visita 20 de abril de 2016 www.elpais.com/tag/autodefensas mexicanas/a/1.

CALDERÓN, Verónica (2014b). "El gobierno mexicano pide a las autodefensas que vuelvan a sus pueblos". Visita 24 de abril de 2016 www.elpais.com/tag/autodefensas mexicanas/a/1.

CALDERÓN, Verónica (2014c). "Militares y autodefensas se enfrentan en Michoacán”. Visita 12 de abril de 2016 www.elpais.com/tag/autodefensas mexicanas/a/1.

CALDERÓN, Verónica (2014d). "La tensión entre soldados y civiles en el suroeste de México se recrudece" Visita 26 de abril de 2016 www.elpais.com/tag/autodefensas_mexicanas/a/1.

CAMACHO, Fernando (2014). "Advierte experto de la ONU que en Michoacán no bastan medidas policiacas". Visita el 4 de abril de 2016 htpp://www.jornada.unam.mx/ultimas/2014/01/30/advierteexperto-de-la-onu-que-en-michoacan-no-bastan-medidas-policiacas-6403.html

CAMARENA, Salvador (2014). "Las autodefensas de Michoacán no son un grupo de delincuentes". Visita el 20 de abril de 2016 www.elpais.com/tag/autodefensas mexicanas/a/1.

CASTELLANOS, Laura (2014a). “Autodefensas "limpian” 22\% de Michoacán”. Visita 25 de abril de 2016 http://archivo.eluniversal.com.mx/nacion-mexico/2014/impreso/autodefensas-limpian-22-demichoacan-213400.html.

CASTELLANOS, Laura (2014b). "Nos van a mochar la cabeza". Visita 19 de abril de 2016 http://archivo.eluniversal.com.mx/nacion-mexico/2014/impreso/-8220nos-van-a-mochar-la-cabeza- 
CASTELLANOS, Laura (2014c). "El retorno de los comunitarios desterrados". Visita 19 de abril de 2016 http://archivo.eluniversal.com.mx/nacion-mexico/2014/impreso/el-retorno-de-los-comunitariosdesterrados-213990.html

CASTEL, Robert (2013). "Políticas del riesgo y sentimiento de inseguridad”. En Robert Castel, Gabriel Kessler, Denis Merklen y Numa Murard. Individuación, precariedad, inseguridad ¿Desinstitucionalización del presente? Buenos Aires: Paidós, pp. 33-43.

CASTEL, Robert (2004). La metamorfosis de la cuestión social. Una crónica del salariado. Buenos Aires: Paidós.

CASTEL, ROBERT y HAROCHE, Claudine (2003). Propiedad privada, propiedad social, propiedad de sí mismo. Conversaciones sobre la construcción del individuo moderno. Rosario: HomoSapiens Ediciones.

CHIGNOLIA, Sandro (2016). “Sobre el dispositivo, Foucault, Agamben, Deleuze”. En Castro, Rodrigo y Salinas, Adán (Eds.). La actualidad de Michel Foucault. Madrid: Escolar y mayo editores.

CHOUZA, Paula (2014). "El doctor que dijo basta a los narcos". Visita 30 de abril de 2016 www.elpais.com/tag/autodefensas mexicanas/a/1

CHOUZA, Paula (2014b). "Detenido José Manuel Mireles, el rosto más visible de la autodefensas en México". Visita el 6 de mayo de 2016 www.elpais.com/tag/autodefensas_mexicanas/a/1

CHOUZA, Paula (2013). “El infierno está en Michoacán”. Visita 18 de abril de 2016 www.elpais.com/tag/autodefensas mexicanas/a/1.

CONSTITUCIÓN POLÍTICA ESTADOS UNIDOS MEXICANOS (2016). México: Lectorum.

COLLIN, Randall (2009). Perspectiva Sociológica. Quilmes: Universidad Nacional de Quilmes.

DAS, Veena (2016). Violencia, cuerpo y lenguaje. México: FCE.

DE LLANO, Pablo (2013). "la crisis de la narcoviolencia. Hunde en la sospecha al gobierno de Michoacán”. Visita 18 de abril de 2016 www.elpais.com/tag/autodefensas mexicanas/a/1.

DE MAULEÓN, Héctor (2014). "Los secretos de Michoacán. Entrevista con Alfredo Castillo”. En nexos. No. 444: 15-21.

DELGADO, Oscar (2013). "Grupos de autodefensa nacen por falta de autoridad". Visita el 20 de mayo de 2016 http://temas-de-interes/impunidad/781-grupos-de-autodefensa-nacen-por-falta-de-autoridad DIARIO OFICIAL DE LA FEDERACIÓN (2011). 15 de noviembre. México.

DUHAU, Emilio y GIGLIA, Ángela (2008). Las reglas del desorden. Habitar la metrópoli. México: Siglo XXI/UAM Azcapotzalco. 
DURAND, Víctor (2010). Desigualdad social y ciudadanía precaria ¿Estado de excepción permanente? México: IIS UNAM-Siglo XXI editores.

DOMÍNGUEZ, Héctor (2015). Nación criminal. Narrativas del crimen organizado y el Estado mexicano. México: Ariel.

ESCALANTE, Fernando (2012). "Crimen organizado. La dimensión imaginaria”. En nexos. No. 418: $32-44$.

EWICK, Patricia y SILBEY, S. Susan (1998). The common place of law: Stories from everday life. Chicago: University of Chicago Press.

FERRER, Eduardo (2014). "Líder de autodefensas de Michoacán se accidenta en avioneta; esta grave". Visita el 28 de abril de 2016 http://www.jornada.unam.mx/ultimas/2014/01/04/lider-de-autodefensasde-michoacan-se-accidenta-en-avioneta-esta grave-2976.html

GERGEN, Kenneth y GERGEN, Mary (2011). Reflexiones sobre la construcción social. Madrid: Paidós.

GREERTZ, Clifford (2006). La interpretación de las culturas. Barcelona: Gedisa editorial.

GLEDHILL, John (2016). La nueva guerra contra los pobres. La producción de inseguridad en Latinoamérica. Barcelona: Ediciones Bellaterra.

GUARDIOLA, Andrés (2013). “Álvaro Uribe: detengan a autodefensas”. Visita el 26 de abril de 2016 http://www.excelsior.com.mx/nacional/2013/05/18/899733

HABERMAS, Jürgen (1999). Teoría de la acción comunicativa II. Crítica de la razón funcionalista. Madrid: Taurus.

KRAUZE, Enrique (2014). "Historias de Tierra Caliente". Visita el 4 de mayo de 2016 http://elpais.com/elpais/2014/02/10/opinion/1392050080 576624.html

KUPER, Adam (2001). Cultura. La versión de los antropólogos. Barcelona: Paidós

LEMUS, Jesús (2015). Tierra sin dios. Crónica del desgobierno y la guerra en Michoacán. México: Grijalbo.

MALDONADO, Salvador (2014). "“'You don't see any violence here but it leads to very ugly things": forced solidarity and silent violence in Michoacán, Mexico". En Dialect Anthropology. No. 38: 153171.

MALDONADO, Salvador (2010). Los márgenes del Estado mexicano. Territorios ilegales. Desarrollo y violencia en Michoacán. Zamora: El Colegio de Michoacán.

MAERKER, Denise (2014a). “Auxilio, ¿Dónde está el Estado?”. En nexos. No. 436: 21-32. 
MAERKER, Denise (2014b). "Vallejo no puede volver". Visita el 25 de abril de 2016 http://www.eluniversalmas.com.mx/columnas/2014/06/107413.php.

MARTÍNEZ, Fabiola (2013). "No es con autodefensas como se soluciona la violencia en Michoacán: Campa". Visita el 28 de abril de 2016 www.jornada.unam.mx/ultimas/2013/12/04.

MARTÍNEZ ELORRIAGA, Ernesto (2015). "Muchos "odiaban" al candidato de Morena asesinado:

PGJ de Michoacán”. Visita el 28 de abril de 2016 http://www.jornada.unam.mx/ultimas/2015/05/15/velan-a-candidato-de-morena-asesinado-enmichoacan-5115.html

MARTÍNEZ ELORRIAGA, Ernesto (2014). “Autodefensas tienen presencia en la sexta parte del territorio de Michoacán: Inegi”. Visita el 29 de abril de 2016 http://www.jornada.unam.mx/ultimas/2014/01/07/autodefensas-tienen-presencia-en-la-sexta-partedel-territorio-de-michoacan-inegi-9261.html

MARTÍNEZ ELORRIAGA, Ernesto (2013). "Llegan autodefensas al municipio de Churumuco, en Michoacán”. Visita el 28 de abril de 2016 www.jornada.unam.mx/ultimas/2013/12/29.

MÉNDEZ, Alfredo (2013). "Los caballeros templarios proponen al gobierno dejar armas si garantiza seguridad en Michoacán”. Visita el 28 de abril de 2016 www.jornada.unam.mx/ultimas/2013/11/27 MICHEL, Elena (2014). "Entrevista. "Viene de años atrás crisis de Michoacán"”. Visita el 25 de abril de 2016 http://archivo.eluniversal.com.mx/nacion-mexico/2014/-entrevista-34viene-de-años-atrascrisis-de-michoacan-34-984138.html

MUEDANO, Marcos (2014a). "Michoacán estrena policía rural estatal”. Visita el 25 de abril de 2016 http://archivo.eluniversal.com.mx/primera-plana/2014/impreso/michoacan-oficializan-fuerza-ruralestatal-45311.html

MUEDANO, Marcos (2014b). "Fuerzas rurales, infiltradas por "Los Templarios", dice Mireles". Visita el 25 de abril de 2016 http://archivo.eluniversal.com.mx/nacion-mexico/2014/impreso/fuerzas-ruralesinflitradas-por-8216los-templarios-8217-dice-mireles-215956.html

MUEDANO, Marcos (2014c). "Mireles: no me siento seguro". Visita el 25 de abril de 2016 http://archivo.eluniversal.com.mx/primera-plana/2014/impreso/8220solo-tengo-mi-vida-y-la-quieroconservar-8221-45334.html

NEOCLEOUS, Mark (2010). La Fabricación del Orden Social. Una teoría crítica sobre el poder de policía. Buenos Aires: Prometeo libros.

NOTICIARIOS TELEVISA (2013). "Las autodefensas, un fenómeno que no es nuevo". Visita el 21 de abril de 2016 http://noticieros.televisa.com/mexico/1309/autodefensas-fenomeno-no-es-nuevo/ 
OTERO, Silvia (2014). ““Ley débil” propició las autodefensas: HRW”. Visita el 21 de mayo de 2016 http://archivo.eluniversal.com.mx/nacion-mexico/2014/impreso/-82201ley-debil-8221-propicio-lasautodefensas-hrw-212400.html.

PANTERS, Wil (2012). Violence, coercion, and State-Making in Twentieth-Century Mexico. Stanford: Stanford University Press.

PARTLOW, Joshua (2014). "Migrantes que no regresaron a EU se unieron a autodefensas: TWP". Visita 29 de abril de 2016 http://www.jornada.unam.mx/ultimas/2014/01/19migrantes-que.noregresaron-a-eu-se-unieron-a-la-lucha-contra-los-templarios-en-michoacan-twp-385.html

PRADOS, Luis (2013). "Guerra de pobres en Tierra Caliente". Visita 18 de abril de 2016 www.elpais.com/tag/autodefensas_mexicanas/a/1.

RAMÍREZ, Carlos (2011). Mexican drugs. Cultura popular y narcotráfico. Madrid: Lengua de Trapo. SICILIA, Javier (2014). "Escuchen lo que dicen las autodefensas". Visita el 2 de mayo de 2016 http://internaciconal.elpais.com/internacional/2014/01/23/actualidad/1390496507_851094

SILBEY, Susan S., y CCAVICCHI, Ayn (2005). "The Common Place of Law. Transforming Matters of Concern into the Objects of Everyday Life". En Bruno Latur y Peter Weibel (Editores). Making Things Public: Atmospheres of Democracy Cambridge: The MIT Press.

SOTELO, Ignacio (2010). El Estado social. Antecedentes, origen, desarrollo y declive. Madrid: Editorial Trotta/Fundación Alfonso Martín Escudero.

STANDING, Guy (2013). El precariado. Una nueva clase social. Barcelona: Pasado\&Presente.

TEJEDA, Armando (2014). "Conflicto en Michoacán no ha afectado ni preocupa al sector turístico: Sectur". Visita 29 de abril de 2016. http://www.jornada.unam.mx/ultimas/2014/01/22/conflicto-enmichoacan-no-ha-afectado-ni-preocupa-al-sector-turistico-sectur-1671.html

TORRE-CANTALAPIEDRA, Eduardo (2018). "Periodismo, actores sociales y migración: intertextualidad en los discursos periodísticos sobre migración”. Convergencia. No. 77: 201-2017. TOURAINE, Alain (2016). El fin de las sociedades. México: FCE.

VARGAS, Rosa (2014). "Niega Peña Nieto que su gobierno dejó crecer a las autodefensas en Michoacán”. Visita 29 de abril de 2016. http//www.jornada.unam.mx/ultimas/2014/01/22/rechazapena-niero-que-su-gobierno-dejo-crecer-a-las-autodefensas-en-michoacan-3366.html

WACQUANT, Loïc (2009). Castigar a los pobres. El gobierno neoliberal de la inseguridad social. Barcelona: Gedisa editorial.

WACQUANT, Loïc (2000). Las cárceles de la miseria. Buenos Aires: Manantial. 
WOLDENBERG, José (2012). La transición democrática en México. México: El Colegio de México, A. C.

ZEPEDA, Jorge (2014). "Robin Hoods con Kaláshnikovs". Visitado el 20 de abril de 2016 www.elpais.com/tag/autodefensas mexicanas/a/1.

Trabalho enviado em 23 de janeiro de 2019

Aceito em 31 de janeiro de 2020 